Disponível em:

http://editora.unoesc.edu.br/index.php/race

Race, Joaçaba, v. 15, n. 3, p. 797-820, set./dez. 2016

\title{
TECHNICAL DEBT EM PROJETOS DE GOVERNO ELETRÔNICO NO ESTADO DO RIO GRANDE DO SUL
}

Technical debt in Rio Grande do Sul e-government projects

Deisy Cristina Barbiero Klein

E-mail: deisy.klein@gmail.com

Especialista em Gestão Estratégica de TI pela Pontifícia Universidade Católica do Rio Grande do Sul; Especialista em Gestão Empresarial pela Universidade Luterana do Brasil; Consultora de Tecnologia da Informação e Gerente de Projetos Governamentais.

Rodrigo Hickmann Klein

E-mail: rodrigo.hickmann@acad.pucrs.br Mestre em Administração e Negócios pela Pontifícia Universidade Católica do Rio Grande do Sul; Doutorando em Administração pela Pontifícia Universidade Católica do Rio Grande do Sul; Consultor de Infraestrutura de Tecnologia da Informação e Arquitetura de Software.

\section{Edimara Mezzomo Luciano}

E-mail: eluciano@pucrs.br Doutora em Administração pela Universidade Federal do Rio Grande do Sul; Pós-doutoranda na London School of Economics and Social Sciences; Professora Titular da Faculdade de Administração, Contabilidade e Economia (FACE) da Pontifícia Universidade Católica do Rio Grande do Sul. Endereço para contato: Avenida Ipiranga, 6681, 90619-900, Partenon, Rio Grande do Sul.

Artigo recebido em 06 de dezembro de 2015. Aceito em 27 de junho de 2016. 


\section{Resumo}

Technical Debt (Dívida Técnica) em Tecnologia da informação (TI) é a dívida assumida pela equipe de projetos de desenvolvimento de software ao adotar uma solução de design ou abordagem fácil de implementar, o que é positivo em curto prazo, mas com impacto muito negativo em longo prazo. O objetivo com a pesquisa foi compreender como os profissionais de TI identificam, abordam, caracterizam, compreendem e tratam a Dívida Técnica. O instrumento de pesquisa desenvolvido por Lim, Taksande e Seaman (2012) foi usado para a coleta de dados mediante uma pesquisa exploratória e qualitativa por meio de entrevistas com profissionais de TI que trabalham em projetos de Governo Eletrônico no Governo do Estado do Rio Grande do Sul. Foram identificadas as percepções relacionadas às causas, sintomas e impactos da Dívida Técnica e sua relação com o custo e o tempo de gestão. Os resultados mostram que a Dívida Técnica está presente nos projetos de Governo Eletrônico analisados, principalmente, para priorizar o escopo e a duração, trazendo alguns riscos para a qualidade de sistemas, integridade de dados e disponibilidade de serviços governamentais. Mesmo que os resultados estejam relacionados a um caso particular, eles mostram a importância da redução da Dívida Técnica ao mesmo tempo que orçamento, abrangência e prazo são considerados. Especialmente em projetos de governo eletrônico, a Dívida Técnica pode comprometer alguns serviços aos cidadãos em longo prazo, exigindo esforço extra para reparos.

Palavras-chave: Technical Debt. Dívida Técnica. e-GOV. Projetos de TI.

\section{Abstract}

Technical Debt in IT is the debt incurred by the team of software development projects by adopting a design solution or easy approach to implement, which is positive in the short term, but has very negative impact in the long-term. The goal of this research is understand how IT professionals identify, approach, characterize, understand and treat Technical Debt. The research instrument developed by Lim, Taksande e Seaman (2012) was used for the data collection through qualitative exploratory interviews with IT professionals who work on E-government Projects from the Rio Grande do Sul State Government. Perceptions related to the causes, symptoms and impacts of the Technical Debt and its relationship to the management cost and time were identified. The results show that Technical Debt is present in the e-government projects analysed mainly to prioritize the scope and term, bringing some risks to systems quality, data integrity and, to the availability of government services. Even though the results are related to a particular case, they show the importance of reducing Technical Debt as long as staying on budget, scope and term especially in E-government Projects since Technical Debt can in the long-term compromise some services to citizens, demanding extra effort for repairs.

Keywords: Technical Debt. e-GOV. IT projects. 


\section{INTRODUÇÃO}

O termo Technical Debt (Dívida Técnica) tornou-se popular em 1992 por meio de Cunningham (1992), que classificou as violações de boas práticas de arquitetura e codificação como "dívida”, assumida pela equipe de desenvolvimento de software ao escolher um design ou abordagem fácil de implementar em curto prazo, mas com impacto muito negativo em longo prazo. Desde então, vários autores como Lim, Taksande e Seaman (2012), Seaman et al. (2012), Curtis, Sappidi e Szynkarski (2012), Fowler (2009a, e 2009b), McConnell (2007), entre outros, têm buscado aprimorar e melhor definir, descrever e entender como a Dívida Técnica tem sido tratada.

Segundo os conceitos de Cunningham (1992), o desenvolvimento de qualquer sistema é passível de contrair uma Dívida Técnica, portanto, é muito importante para o sucesso de um sistema permitir a tomada de decisões fundamentadas em boas práticas de arquitetura e codificação de software. Na busca de obter o contexto da Dívida Técnica e como os profissionais da área de TI a percebem, Lim, Taksande e Seaman (2012) realizaram um estudo no qual foram encontrados resultados importantes para a compreensão da Dívida Técnica.

Os projetos de sistemas de informação para o Governo Eletrônico (e-GOV) possuem um enfoque mais social, quando comparados a demais projetos, pois segundo Kumar et al. (2007), a utilização de tecnologias a serviço de instituições governamentais tem como objetivo, mesmo que indiretamente, melhorar a qualidade de vida dos cidadãos, redefinindo a relação que estabelecem com o Governo. De acordo com o relatório da Organização das Nações Unidas (2012), a existência de serviços on-line na área governamental pode aumentar significativamente a acessibilidade, bem como economizar o tempo e o dinheiro dos cidadãos. O relatório conclui que a esfera de governo eletrônico precisa ser analisada e repensada, a fim de encontrar a melhor maneira de satisfazer as necessidades reais dos cidadãos, pois os projetos de Governo Eletrônico devem implicar a configuração e utilização de tecnologias, sistemas de informação, com o objetivo de mudar ou adaptar os seus processos administrativos, maximizando a qualidade da interação, ao promoverem seus serviços e informação com os cidadãos, empresas ou outros órgãos governamentais. Entretanto, os projetos de Governo Eletrônico têm dificuldade em contar com o envolvimento direto dos usuários finais na especificação dos produtos dos projetos e caracterizam-se pela dificuldade do feedback relativo à qualidade dos sistemas implantados (ANTHOPOULOS et al., 2015). 
No presente artigo utilizou-se o instrumento de pesquisa dos autores Lim, Taksande e Seaman (2012) em um novo contexto, obtendo-se uma perspectiva atual e local sobre esse assunto, em projetos de e-GOV. Teve-se como objetivo principal descobrir como os profissionais da área de TI, em um contexto local, identificam, abordam, caracterizam, entendem e tratam a Dívida Técnica, pois compreender as causas, os sintomas e os efeitos desta em projetos de e-GOV possibilita que ela possa ser mais bem compreendida, favorecendo o seu gerenciamento mais adequado e destacando a importância que o assunto deve ter para gestores profissionais da área de TI.

Na primeira parte do artigo é apresentado um referencial teórico, uma introdução à Technical Debt (Dívida Técnica). Em seguida, descreve-se a metodologia de pesquisa utilizada. Na terceira parte, é feita a análise dos dados coletados e um comparativo dos resultados obtidos entre os dois estudos. Por fim, apresentam-se as considerações finais.

\section{REFERENCIAL TEÓRICO}

Esta seção é uma introdução à Technical Debt (Dívida Técnica) na visão de alguns autores; posteriormente, são apontadas abordagens para serem utilizadas no planejamento de tomada de decisões para o pagamento da Dívida Técnica assumida; e, por fim, são apresentadas algumas considerações com a adoção da Dívida Técnica.

\subsection{CONCEITOS DE DÍVIDA TÉCNICA}

A aplicação da expressão Technical Debt (Dívida Técnica) na área de desenvolvimento de software ganhou evidência após a apresentação de Cunningham (1992), que relatou sua experiência no desenvolvimento de software para a área financeira. Durante esse desenvolvimento, ele se deparou com o dilema de postergar as boas práticas de desenvolvimento, em razão do tempo necessário para a entrega do software, ou de implementar as boas práticas de desenvolvimento e não contrair uma Dívida Técnica para o futuro, porém, com a possibilidade de comprometer o prazo de entrega. Dessa forma, Cunningham classificou como “dívida” as violações de boas práticas de codificação e de arquitetura de software, na busca de um resultado imediato. Nessa circunstância, o software entregue até pode funcionar bem e ser completamente aceitável pelo cliente, mas será uma programação ou arquitetura imatura que precisará ser corrigida ou aprimorada futuramente, caracterizando, assim, uma “dívida” assumida pela equipe de desenvolvimento ou empresa desenvolvedora. 
Desde então, a Dívida Técnica vem sofrendo novas abordagens, assim como novas formas de identificá-la e gerenciá-la estão sendo adotadas, a partir de estudos que estão sendo realizados e, até mesmo, pelo reconhecimento e pela importância atribuídos ao assunto por diferentes autores e profissionais da área de TI.

McConnell (2007) busca traduzir a Dívida Técnica para uma linguagem mais compreensível, categorizando esse conceito técnico fundamental em dois tipos básicos:

a) dívida contraída sem intenção: em razão de trabalhos de baixa qualidade;

b) dívida contraída intencionalmente: ocorre quando uma organização toma uma decisão consciente para adotar uma solução que priorize o atendimento das necessidades da demanda no presente, sabendo que essa solução resultará em consequências que precisarão ser resolvidas no futuro. Subdivide-se em dívida de curto prazo, usualmente incorrida reativamente, por razões táticas, como atalhos individualmente identificáveis; e, em dívida de longo prazo, geralmente incorrida de forma proativa, por razões estratégicas.

Já Fowler (2009a) buscou identificar questões de tipo de falhas de projetos que devem ou não ser classificadas como Dívida Técnica. Para o autor, a dívida é útil para lidar com problemas de projeto e fazer a sua comunicação, tornando-se útil para se comunicar com pessoas não técnicas. Fowler (2009b) criou o Quadrante da Technical Debt, exibido na Figura 1, para demonstrar uma possível forma de classificação da dívida, pelo enfoque da natureza da dívida. Separou a dívida nas seguintes categorias:

Figura 1 - Quadrante da Technical Debt

\begin{tabular}{|c|c|}
\hline $\begin{array}{c}\text { Imprudente } \\
\text { "Nós não temos tempo para planejar." } \\
\text { Intencional }\end{array}$ & $\begin{array}{c}\text { Prudente } \\
\text { "Nós precisamos entregar agora e lidar } \\
\text { com as consequências." }\end{array}$ \\
\hline Sem intenção & "Agora sabemos como devemos fazer \\
"O que são camadas de software?” & isso." \\
\hline
\end{tabular}

Fonte: adaptada de Fowler (2009b). 
a) Prudente: quando a equipe de desenvolvimento opta por ter falhas de projeto no código, ou seja, a dívida é proposital, a equipe sabe que está assumindo a dívida. Possui dois enfoques diferentes:

- prudente - intencional: quando a equipe de desenvolvimento toma suas decisões depois de avaliar os seus benefícios e consequências;

- prudente - sem intenção: quando a equipe de desenvolvimento percebe a melhor abordagem, depois de possuir alguma experiência e conhecimento do trabalho a ser realizado;

b) imprudente: quando a equipe de desenvolvimento gera um código imaturo, resultando em altos juros. Com dois enfoques diferentes:

- imprudente - intencional: em que a equipe conhece as boas práticas de projeto, sendo capaz de praticá-las, mas decide por não utilizá-las;

- Imprudente - sem intenção: quando a equipe produz o código sem nenhuma consciência de boas práticas de projeto, impactando a produtividade global futura da equipe.

Para Seaman et al. (2012), similarmente a uma dívida financeira, a Dívida Técnica refere-se ao esforço necessário para completar uma tarefa.

Segundo Curtis, Sappidi e Szynkarski (2012), Dívida Técnica deve ser vista como o custo de corrigir problemas estruturais de qualidade em código já implantados no cliente, os quais a organização sabe que deve eliminá-los para controlar os custos de desenvolvimento ou para evitar problemas operacionais. Curtis, Sappidi e Szynkarski (2012) procuram diferenciar Dívida Técnica de defeitos ou falhas. Falhas durante o teste ou a utilização do software podem ser sintomas de Dívida Técnica, porém, a maioria das falhas estruturais gera Dívida Técnica.

Nesse sentido, Kruchten, Nord e Ozkaya (2012) reforçam que, na maioria das vezes, a dívida técnica não está relacionada ao código e às suas qualidades intrínsecas, mas às escolhas estruturais ou arquitetônicas e às lacunas tecnológicas. Algumas dessas falhas estruturais podem nunca ser detectadas nos testes ou na utilização do software, mas podem tornar a aplicação menos eficiente e menos escalável, dificultando a realização de manutenções evolutivas e corretivas, ou deixando o sistema mais vulnerável em relação à Segurança da Informação (CURTIS; SAPPIDI; SZYNKARSKI, 2012).

\subsection{ADOÇÃO DA DÍVIDA TÉCNICA}

Para atender com eficiência e rapidez às exigências de mercado, as empresas e equipes de desenvolvimento tiveram que se adaptar à nova realidade. Segundo 
Cunningham (1992), o cliente valorizava mais a capacidade de resposta do que as suas necessidades atendidas, o que resulta em decisões que focam em obter vantagens em um curto prazo e na possibilidade de desvantagens em longo prazo.

Assumir uma Dívida Técnica acelera o desenvolvimento (CUNNINGHAM, 1992) e garante que o prazo de entrega seja respeitado, proporcionando vantagem em curto prazo, mas é muito importante garantir, que ao assumir essa dívida, não resulte em algo que gerará prejuízo em longo prazo. Cunningham (1992) considerou a dívida não paga um perigo para as empresas de desenvolvimento de software, pois cada minuto gasto em algo não realizado da maneira correta conta como juros que aumentam a dívida. Curtis, Sappidi e Szynkarski (2012) concordam com esse conceito e acrescentam que corrigir a Dívida Técnica requer programação e esforço que poderiam ter sido dedicados à criação de uma nova funcionalidade de negócios. O esforço empenhado em se pagar a Dívida Técnica representa um custo de oportunidade proveniente dos benefícios perdidos que poderiam ter sido alcançados pela empresa.

Conforme descrito, percebe-se que a Dívida Técnica tem sido utilizada costumeiramente pelas equipes de desenvolvimento, gestores, profissionais e empresas de TI, que diante das exigências de mercado e de clientes, buscam manter um equilíbrio para o desenvolvimento de um produto com qualidade, o qual atenda às necessidades especificadas pelo cliente e que seja entregue em prazo razoável e com um custo justo para a empresa e o cliente.

\subsection{PAGAMENTO DA DÍVIDA TÉCNICA}

Conforme Seaman et al. (2012), a prática atual no desenvolvimento e manutenção de software envolve decisões difíceis na priorização de tarefas perante grandes limitações de recursos. Essas decisões geralmente se concentram em mudanças e manutenções que possuem impacto imediato sobre o funcionamento dos recursos de sistemas, podendo ser melhorias ou correção de defeitos, acarretando impactos na viabilidade financeira do produto, resultando em uma Dívida Técnica. Tal dívida nem sempre é considerada no processo de tomada de decisões, pois, muitas vezes, não é apresentada para os tomadores de decisão. No entanto, há muitos exemplos de projetos de desenvolvimento de software em que a desatenção ao monitoramento da Dívida Técnica resultou em custos excedidos inesperadamente altos, em problemas graves de qualidade e em impossibilidade de adicionar novos recursos de software sem prejudicar os recursos existentes. 
Para Kruchten, Nord e Ozkaya (2012), o profissionalismo, a diligência, a dedicação e a habilidade certamente ajudarão a pagar a dívida, mas não são determinantes. Seaman et al. (2012) enfatizam que as informações sobre a Dívida Técnica devem ser incorporadas à tomada de decisão, havendo a necessidade de construir uma teoria a respeito de Dívida Técnica, sobre a qual podem ser desenvolvidas abordagens e mecanismos para facilitar essa tomada de decisão.

Para Bavani (2012), a gestão da dívida técnica afeta diretamente a economia em manutenções de software. Com o propósito de facilitar a tomada de decisão de quais itens da Dívida Técnica devem ser pagos em curto prazo, Seaman et al. (2012) sugerem quatro abordagens de decisão que podem ser usadas para a geração de um planejamento: Análise Simples de Custo-Benefício, Processo Analítico Hierárquico (AHP), Abordagem de Portfólio e Opções de pagamento.

A Análise Simples de Custo-Benefício é uma abordagem de gerenciamento central em uma “lista da Dívida Técnica.” Essa lista contém itens da Dívida Técnica que representam uma tarefa que foi deixada de lado, mas que corre o risco de causar problemas futuros se não for concluída. Cada item inclui uma descrição de localização desse débito no sistema, o motivo pelo qual a tarefa precisa ser feita, as estimativas do montante e os juros. Quando um item da Dívida Técnica é criado, todas as três métricas - dívida, probabilidade de juros e montante de juros - recebem valores estimados como: alto, médio ou baixo. Baseado nessas informações, o gestor poderá tomar decisões preliminares. Entretanto, Seaman et al. (2012) recomendam a utilização de estimativas mais precisas, com procedimentos de estimação para cada métrica baseados no tipo de item de Dívida Técnica.

O Processo Analítico Hierárquico (AHP) fornece um método simples para a estruturação de um problema, comparando alternativas em relação aos critérios especificados, e determina uma classificação geral para cada alternativa, sendo eficaz tanto para multicritérios quanto para a construção de cenários para a decisão em grupo. Aplicar AHP envolve a construção de uma hierarquia de critérios - que inclui todos os critérios quantitativos e qualitativos, objetivos e subjetivos, que são relevantes para a decisão a ser feita - atribuindo pesos e escalas aos critérios e realizando uma série de comparações de pares entre as alternativas e os diversos critérios. Na gestão da Dívida Técnica as alternativas de decisão seriam baseadas nos casos identificados da dívida atualmente existentes no sistema. O resultado do processo seria um ranking de prioridades desses itens, indicando qual deve ser pago primeiro. Os critérios estão relacionados às noções da dívida e dos juros, alguns dos quais são incertos e subjetivos, sendo necessária alguma intervenção humana, principalmente quando é obrigatório 
fornecer informação que não pode ser mensurada de forma confiável. Para Seaman et al. (2012), a utilização de AHP na tomada de decisão para pagamento da Dívida Técnica fornecerá um mecanismo eficiente e eficaz para a estruturação, minimizando a intervenção humana nesse processo.

A Abordagem de Portfólio refere-se a um conjunto de ativos detidos por um investidor. O portfólio é, normalmente, usado como uma estratégia de redução de risco por parte dos investidores. O gerenciamento de portfólio é um processo de tomada de decisão que consiste em determinar os tipos e quantidades de recursos que deveriam ser investidos ou alienados, sendo muito semelhante ao processo de gestão da Dívida Técnica, em que os responsáveis necessitam tomar decisões sobre quando e quais itens da dívida devem ser pagos ou mantidos. Em razão da incerteza envolvida, o retorno esperado e a variância do retorno são frequentemente utilizados para avaliar o desempenho dos ativos. Essa avaliação pode ser realizada de forma qualitativa, se o valor futuro de um ativo é altamente incerto, ou em uma base quantitativa utilizando modelos matemáticos, se as informações para obter o valor futuro estão disponíveis.

O objetivo da gestão de portfólio é selecionar o conjunto de ativos que pode maximizar o retorno sobre o investimento ou minimizar o risco do investimento. $\mathrm{O}$ portfólio possui ativos que variam de liquidez e são sensíveis às mudanças do mercado, normalmente apresentam diferente volatilidade e padrões de desempenho. Possuir um portfólio de ativos, com uma diversificação do investimento, é menos arriscado do que investir em um único ativo. Com base no princípio da diversificação, foram propostos vários modelos de portfólio (SEAMAN et al., 2012).

A Teoria de Portfólio Moderno é um exemplo de modelo de análise da média variância, que usa o retorno esperado e a variância de retorno para medir o desempenho de um portfólio. Conforme Seaman et al. (2012), essa abordagem apresenta alguns pressupostos que são específicos para o domínio financeiro, e, para ser aplicada na gestão da Dívida Técnica, seriam necessárias algumas adaptações.

As opções de pagamento de um item da Dívida Técnica, como, por exemplo, a refatoração da programação de um software, podem ser vistas como uma decisão de investimento, em que incorrem relativamente certos custos de curto prazo - compromisso de tempo, dinheiro e/ou recursos - na busca de benefícios de longo prazo, na forma de manutenção de redução de custos. A decisão do investimento será baseada analisando-se o potencial técnico das opções existentes, por exemplo, a aquisição da opção que facilita a mudança para o software no futuro se o software tem de ser alterado, mas sem lucro imediato. Para Seaman et al. (2012), nessa abordagem existe a dificuldade de quantificar o potencial técnico, devendo ser necessário mensurar a 
compensação de custos dos benefícios da melhoria do módulo, em que os módulos independentes, que são a grande maioria, com alto valor potencial técnico, têm os mais altos valores de opção.

\section{METODOLOGIA}

O presente trabalho é uma pesquisa exploratória qualitativa, à qual se utilizou o instrumento desenvolvido por Lim, Taksande e Seaman (2012).

O levantamento dos dados foi realizado por meio de entrevistas semiestruturadas e administradas pelos autores, utilizando o mesmo formato de entrevista com o mesmo roteiro (guia) para a realização das entrevistas (disponível no Apêndice A). Todas as entrevistas foram realizadas na forma presencial, gravadas e posteriormente transcritas. Foram realizadas 14 entrevistas semiestruturadas, entre outubro e novembro de 2013, compondo uma amostragem não aleatória por conveniência, com resultados não generalizáveis (HAIR JUNIOR, et al., 2005), mas que refletem um contexto específico em projetos de Governo Eletrônico. Todos os respondentes são profissionais da área de TI em projetos de e-GOV no Estado do Rio Grande do Sul nas áreas de tributos e finanças públicas governamentais e de saúde.

Quanto à análise dos dados, no estudo atual procurou-se utilizar as mesmas categorias e subcategorias utilizadas no estudo anterior, ou seja, primeiramente utilizando um conjunto de categorias pré-formadas (atributos, sintomas, causas e consequências) e posteriormente acrescentando subcategorias e códigos que surgiram dos dados. Para auxiliar a análise dos dados foi utilizado o software Atlas TI Versão 7.

No início da entrevista obtinha-se do respondente se a expressão Technical Debt (Dívida Técnica) era conhecida, apenas três respondentes estavam familiarizados com ela. No entanto, todos receberam uma breve explicação do assunto, reforçando o conhecimento dos que já estavam familiarizados e criando o conhecimento para os que ainda não estavam, sendo facilmente compreendido por todos, proporcionando um nivelamento básico do assunto para todos os respondentes.

Diferentemente do estudo anterior, todas as entrevistas no estudo atual foram realizadas na forma presencial; em ambos os estudos foram gravadas e transcritas posteriormente. Outra diferença existente nos estudos refere-se aos dados demográficos de gênero. No estudo anterior a grande maioria dos respondentes era do gênero masculino, já no estudo atual a grande maioria dos respondentes era do gênero feminino. Assim como o papel no projeto, que no estudo anterior prevaleceu o de desenvolvedores, no estudo atual o papel que prevaleceu foi o de analista de sistemas. 


\subsection{CATEGORIZAÇÃO DOS RESPONDENTES}

A pesquisa foi realizada com 14 respondentes, nove do sexo feminino e cinco do sexo masculino, ambos com ampla experiência na área de TI. Os respondentes selecionados atuam em três organizações distintas, sendo duas delas prestadoras de serviço da área de TI e uma da área de saúde. Mesmo que alguns respondentes pertençam à mesma empresa, todos os respondentes participam de projetos diferentes dentro das empresas em que atuam.

Na Tabela 1 exibe-se o papel no Projeto que o respondente exerce.

\begin{tabular}{ll} 
Tabela 1 - Papel no Projeto & \\
\hline Papel no Projeto & \multicolumn{1}{c}{ Respondentes } \\
\hline Gerente de Projetos & 2,11 \\
Analista de Sistemas & $3,6,7,8,10,13,14$ \\
Líder de Equipe & 1,9 \\
Desenvolvedor & $4,5,12$ \\
\hline
\end{tabular}

Fonte: os autores.

No Gráfico 1 é exibida a classificação quanto à experiência profissional dos respondentes, quantificada em anos.

Gráfico 1 - Experiência Profissional na área de TI

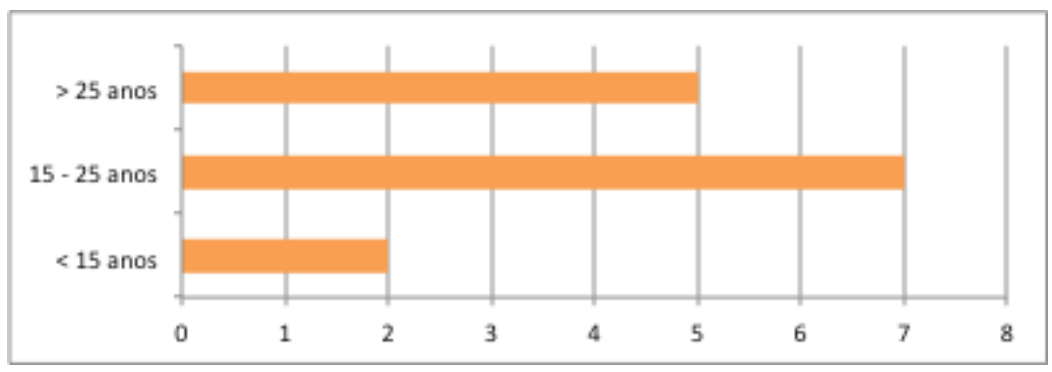

Fonte: os autores.

\section{ANÁLISE DOS RESULTADOS}

A Dívida Técnica, mesmo não sendo uma expressão muito usual para os respondentes do estudo atual, é uma técnica utilizada por todos. Pelo presente estudo foi obtido um material muito informativo e esclarecedor de como esses profissionais 
estão tratando a Dívida Técnica em seus projetos. O questionário semiestruturado proporcionou uma excelente base de levantamento do conteúdo, sendo apresentado em uma forma mais resumida conforme apresentado nesta seção. Na Tabela 2, consta um resumo de categorias embasadas na pesquisa de Lim, Taksande e Seaman (2012).

Tabela 2 - Categorias analisadas

\begin{tabular}{ll}
\hline Categorias & Respondentes \\
\hline A Dívida Técnica permite atender às expectativas dos clien- & 3, 4, 6, 10, 11 e 12 \\
tes, suas necessidades e desejos. & $2,4,8$ \\
A Dívida Técnica é negativa em longo prazo. & $1,7,11,13$ \\
A Dívida Técnica compromete a qualidade. & $7,10,12,14$ \\
A Dívida Técnica possibilita atender ao prazo. & $1,2,3,4,5,6,7,8,9,10,11,12,13,14$ \\
A Dívida Técnica é comunicada aos envolvidos no projeto. & $3,4,5,6,7,12$ e 13 \\
A Dívida Técnica é comunicada ao cliente. & \\
\hline
\end{tabular}
Fonte: os autores.

Para a maioria dos respondentes, a Dívida Técnica é adquirida em razão da necessidade de atender às expectativas do cliente, entregando algo que realmente agregue valor em curto prazo. Para os Respondentes 3, 4, 6, 10, 11 e 12, contrair uma Dívida Técnica proporciona um ganho de tempo para a execução de funcionalidades com maior prioridade para o cliente. No caso relatado pelo Respondente 12 foi mencionado o momento em que é considerado vantajoso assumir uma Dívida Técnica, em face da tarefa que deve ser realizada, de acordo com o grau de prioridade e urgência:

[...] nem tudo que é urgente é prioritário e nem tudo que é prioritário é urgente, isso a gente vê bem claro, ou seja, se eu tenho um erro no meu sistema, mas que pode acontecer, mas não é urgente e nem prioritário neste caso, e eu tenho prioridades que o cliente priorizou, esta é a vantagem de assumir a dívida, assumo um risco, mas tu sabes que vale a pena arriscar para assumir essa dívida porque ganha tempo para as outras coisas mais importantes e que vão agregar valor ao sistema. (informação verbal).

Em uma visão em longo prazo, um fator apontado é a dificuldade da manutenção que deve ser realizada posteriormente no código, como mencionado pelo Respondente 4:

[...] quanto mais dívida técnica tu tem, mais gambiarra vai ficando, e o sistema vai ficando cada vez pior para dar manuten- 
ção depois. Acaba atrapalhando, acaba engessando, porque tu não faz da forma mais certa, então vai se engessando o sistema que lá na frente vai acabar tendo um pouco mais de trabalho, às vezes, ou tu vai ter que corrigir aquilo ou tu vai levar mais trabalho para contornar aquilo. (informação verbal).

Assim como a responsabilidade de garantir o funcionamento correto de uma funcionalidade que esteja apenas sofrendo uma manutenção de melhoria do código, a parte externa que o cliente visualiza permanece inalterada, mas internamente sofre uma grande mudança, podendo comprometer completamente o resultado dessa funcionalidade, conforme mencionado pelos Respondentes 2 e 8.

Nos vários casos relatados pelos respondentes, referentes à Dívida Técnica contraída em seus projetos, os sistemas ainda estavam em desenvolvimento ou recebiam manutenções frequentes, percebe-se que os benefícios em curto prazo superam os custos em longo prazo. Para os casos em que os sistemas são considerados de grande porte, muitos antigos e que já estão em uso pelos clientes, a Dívida Técnica é aceita sem que se consiga perceber vantagem em curto ou em longo prazos, apenas é considerada como algo sem outra alternativa, que não seja aceitar e assumir a dívida.

A necessidade de entregar rapidamente uma determinada funcionalidade, com alto valor agregado e que foi solicitada pelo cliente, pode comprometer a qualidade do software com a geração de código imaturo. Alguns respondentes relatam que essa necessidade tem uma grande influência em forçar a equipe de desenvolvimento a assumir uma dívida técnica. Como relatado pelo Respondente 13: “[...] muitas coisas a gente fazia para entregar, sabendo que podia ser feito de forma melhor.” (informação verbal). Para o Respondente 1: “[...] tu sabe que não está perfeito e que mais adiante vai ter que ser revisto, refeito.” (informação verbal).

Assumir a dívida para atingir tal objetivo, de forma consciente, nem sempre é uma decisão aceita facilmente, como mencionado pelo Respondente 14: “[...] que tu não está fazendo um trabalho bem feito já de cara. Tu tem que assumir que começou falhando, tu começou devendo, isso é péssimo, muito ruim.” (informação verbal).

Para atender à necessidade de redução de custo do projeto, muitas empresas estão fazendo uso de equipes cada vez mais reduzidas, sendo formadas conforme a necessidade e importância do projeto, o que pode implicar o aumento da dívida, como mencionado pelo Respondente 1: “[...] esta dívida é muito superior aos nossos recursos [...], nós estamos sacrificando parte do desenvolvimento para pagar a dívida [...]” No caso relatado pelo Respondente 11, aumentar a equipe foi a solução para possibilitar o pagamento da dívida: “[...] a gente teve um reforço de equipe, mais duas 
pessoas foram colocadas no projeto o que deu este fôlego para poder planejar e atacar a dívida.” (informação verbal).

Como uma possível solução para garantir a qualidade do software, maior agilidade e facilidade no desenvolvimento de sistemas, foi apontada a adoção de um framework, conforme mencionado pelo Respondente 11: “[...] a gente conseguiu criar um framework muito fácil de desenvolver, agilizando o desenvolvimento nesta refatoração que está sendo feita.”

Apesar de os respondentes considerarem ruim a entrega de uma funcionalidade, desenvolvida com baixa qualidade, acabam por assumir essa Dívida Técnica em razão das exigências dos clientes.

Muitos casos relatados pelos respondentes, relativos à Dívida Técnica contraída, remetem-se a necessidade de atender às necessidades dos seus clientes, priorizando a entrega de algo que tenha valor para o cliente. Como relatado pelo Respondente 10: [...] da maneira que a gente trabalha é entregar o que tem valor para o cliente, procuramos não colocar muito os desejos da equipe de desenvolvimento perante os desejos do cliente, porque, muitas vezes, a gente acha que é muito importante, tem que ser feito e para o cliente não é importante.” (informação verbal).

No projeto do Respondente 12, o fato de assumir uma Dívida Técnica proporciona um ganho de tempo, para que as demandas com maior prioridade sejam atendidas.

Nos projetos dos Respondentes 7 e 14, a Dívida Técnica foi vista como uma melhoria, na qual se manteve o comprometimento de entrega com o cliente, respeitando o prazo, atendendo à funcionalidade solicitada, assumindo a responsabilidade de algo funcionando corretamente, mas com melhorias a serem feitas no futuro.

A medição da dívida é um dos pontos de menor relevância para os respondentes, todos sabem da dívida, da necessidade do pagamento dela, mas o foco mais importante, em cada um dos projetos, é atender e satisfazer à necessidade do cliente, entregando sempre algo que agregue valor ao cliente.

Muitos respondentes alegam que um grande perigo de assumir a Dívida Técnica é a falta de controle da dívida, não deixando cair no esquecimento ou correr o risco de se tornar uma dívida eterna. Cadastrar a dívida, como uma tarefa que deve ser realizada, é a técnica utilizada para garantir que a dívida seja paga e não esquecida, como foi mencionado pelo Respondente 4: [...] tem que fazer coisas pequenas, porque se tu deixar pra traz, normalmente, tu não volta, apesar da gente ter cadastrado uma tarefa e estar lá pendente pra gente fazer, se tu não criar tarefa tu faz e nunca mais vai olhar para aquilo, vai ficar lá e ninguém vai saber, mas se tu tiver um controle, cadastrar, tu tiver sempre visualizando ela, um dia vai acabar fazendo.” (informação verbal). 
Também como menciona o Respondente 10 que salienta: “[...] acho que isso é a maior questão, é de organizar, de conseguir ter um maior controle de tudo que tem que ser feito e as coisas serem feitas, não deixar as coisas ficarem esquecidas.”

Quanto à comunicação da dívida, percebe-se que esta é conhecida por todos da camada técnica e gerencial, ou seja, gerentes, chefias, analistas e desenvolvedores, quando o processo de desenvolvimento é realizado internamente na empresa. Entretanto, quando o processo de desenvolvimento utiliza uma empresa externa - como, por exemplo, a contratação de fábrica de software - a comunicação é tratada apenas internamente, pois os respondentes não consideram necessário isso chegar ao conhecimento dos desenvolvedores externos.

A comunicação da dívida é feita ao cliente de acordo com o nível de participação dele no processo de desenvolvimento do projeto, como ocorreu no projeto do Respondente 10, que informa seu cliente sempre nas reuniões de negociações do que deve ser feito na próxima sprint. Nesses casos o cliente participa e atua diretamente no pagamento da dívida, priorizando ou não a execução dela, assim como ocorre nos projetos dos Respondentes 3, 4, 5, 6, 7, 12 e 13.

Nos casos relatados, apenas dois respondentes admitiram que a dívida foi assumida de forma Imprudente - Intencional, todos os demais respondentes expuseram que suas dívidas foram assumidas de forma Prudente, intencional ou sem intenção.

Dez respondentes relataram que a Dívida Técnica é algo que nem sempre é planejado, mas ao surgir, se não for assumida nunca será eliminada, e como consequência tende a aumentar porque a manutenção se torna mais complexa com o passar do tempo. Há circunstâncias em que uma solução adotada como a mais correta no presente se torna uma dívida no futuro, em razão da evolução tecnológica.

Para os respondentes que atuam também como desenvolvedores, destaca-se a resistência em contrair uma Dívida Técnica, buscando sempre uma solução que elimine essa possibilidade, principalmente débitos técnicos que impactem o desenvolvimento de um código com baixa qualidade ou erro, como relatado pelo Respondente 8: "[...] a dívida que se tem quando tem um erro, eu não gosto disso, se eu vejo que tem um erro, tem que ser corrigido.” (informação verbal).

Para os respondentes que assumem apenas o papel de gestores de seus projetos, a Dívida Técnica é aceitável e utilizada, tanto nos projetos cujo sistema já está sendo utilizado pelo cliente quanto para aqueles cujo sistema está em desenvolvimento e necessitam atender ao prazo acordado ou aumentar a credibilidade da empresa com o cliente. Como mencionado pelo Respondente 10: “[...] diria que foi muito bom, 
pois com isso a gente conseguiu diminuir a ansiedade do cliente, à medida que ele via que o projeto estava andando e as coisas estavam acontecendo.” (informação verbal).

Para a maioria dos respondentes a Dívida Técnica é algo inevitável e intencional. O grande desafio é conseguir manter o equilíbrio entre contrair a dívida e pagá-la, equilibrando a realidade dos recursos com a expectativa do cliente, sem afetar a qualidade do software. Nessa situação um gerenciamento eficiente é apontado como a melhor solução. Há muitas técnicas utilizadas pelos respondentes para o gerenciamento da Dívida Técnica:

a) cadastrar a dívida em uma lista de tarefas com status pendente;

b) manter a tarefa sempre visível na lista, nunca remover da lista até que seja realmente paga;

c) garantir a geração de código com alta qualidade, fazendo uso da adoção de framework, manuais de desenvolvimento e boas práticas;

d) possuir uma equipe apta para a execução da tarefa;

e) prover treinamentos para os desenvolvedores;

f) procurar ter uma comunicação direta com o cliente;

g) procurar sempre que possível uma maior participação e envolvimento do cliente.

Nos vários casos de Dívida Técnica relatada pelos respondentes, percebe-se que a dívida assumida está embutida dentro do contexto de cada projeto e que o gerenciamento dessa dívida é baseado nesse contexto, assim, não existe um consenso sobre a forma de gerenciamento da dívida. Entretanto, existem as técnicas supracitadas que podem facilitar esse gerenciamento e serem adaptadas para que um resultado seja alcançado com sucesso.

\subsection{COMPARATIVO ENTRE OS RESULTADOS OBTIDOS}

Seguindo os mesmos critérios de seleção de respondentes e análise utilizados no estudo realizado por Lim, Taksande e Seaman (2012), no estudo atual também se conseguiu obter uma grande quantidade de informações importantes para a maior compreensão da Dívida Técnica. Na Tabela 3 consta um comparativo inicial dos estudos. 
Tabela 3 - Comparativo entre estudos de Lim, Taksande e Seaman (2012) e pesquisa atual

\begin{tabular}{lll}
\hline & Lim, Taksande e Seaman (2012) & $\begin{array}{c}\text { Pesquisa } \\
\text { atual }\end{array}$ \\
\hline Local & British Columbia e Maryland & Porto Alegre \\
N. respondentes & 35 & 14 \\
Companhias/Organizações & 26 & 3 \\
Não familiaridade com Technical Debt & 26 & 11 \\
$\begin{array}{l}\text { Dívida Técnica contraída com desenvolvi- } \\
\text { mento de baixa qualidade, em razão da falta }\end{array}$ & 9 & 1 \\
de disciplina em seguir as boas práticas & &
\end{tabular}

Fonte: os autores.

A comparação entre os dois estudos é importante porque permite identificar que mesmo em outro contexto, com outro perfil de respondentes, os resultados se assemelham, reafirmando as conclusões da pesquisa original. Não obstante, o novo contexto possibilita perceber que o perfil diferenciado dos respondentes amplia o conhecimento sobre as respostas divergentes da pesquisa original.

A análise dessas informações permite que o objetivo específico da geração de um comparativo entre os dois estudos seja realizado, conforme é explanado a seguir:

Todos os respondentes estavam aptos a participar deste estudo. O estudo atual foi realizado com 14 respondentes contra 35 no estudo anterior.

O termo Technical Debt (Dívida Técnica), assim como no estudo anterior, não era familiar a 26 dos respondentes; no estudo atual não era familiar a 11. Diferentemente do estudo anterior, no qual dois respondentes tiveram dificuldades em entender o conceito, no estudo atual o conceito foi facilmente entendido por todos. Em ambas as pesquisas, após a apresentação e compreensão do termo, todos conseguiram identificar ao menos um exemplo de Dívida Técnica nos seus projetos.

Nesse item os resultados obtidos foram muito similares, pois no estudo atual apenas um respondente trata a Dívida Técnica, contraída em seu projeto, como desenvolvimento de baixa qualidade, em decorrência da falta de disciplina em seguir as boas práticas. No estudo anterior, essa foi a resposta para nove dos respondentes. A maioria dos respondentes trata a Dívida Técnica como decisões intencionais, resultantes de um pensamento de curto prazo em reação a pressões do momento.

Em ambos os estudos, os respondentes relataram que ao contrair a Dívida Técnica os benefícios de curto prazo superam os custos em longo prazo; outrossim, relataram que a Dívida Técnica combina com metodologias de desenvolvimento in- 
cremental, com iterações evolutivas, principalmente em sistemas que possuem alterações frequentes em suas especificações durante o desenvolvimento.

Ambos os estudos reconhecem que a realidade do mercado de desenvolvimento de software afeta a qualidade do software, sendo um fator importante para a tomada de decisão de assumir uma Dívida Técnica. Os respondentes de ambas as pesquisas descreveram casos em que os benefícios de atender às exigências do cliente superaram os benefícios da qualidade da programação; nesse caso a qualidade é o grau de atendimento dos requisitos do cliente, em vez de ser o grau de atendimento das melhores práticas em desenvolvimento e arquitetura de software.

Algo comum nas duas pesquisas é o atendimento das expectativas dos clientes, por intermédio de entregas de itens de valor ao cliente. Isso também foi apontado como um influenciador para que a equipe assuma uma Dívida Técnica, conforme os casos relatados por muitos respondentes.

Apenas dois respondentes conseguiram estimar corretamente o valor da dívida, em razão da forma de desenvolvimento utilizada em seus projetos. Um desses casos foi o citado pelo Respondente 12, que mencionou sua experiência em um projeto o qual utilizou a metodologia de desenvolvimento ágil, com sprint de duas semanas. Outro caso foi o citado pelo Respondente 14, que relatou sua experiência em processos de desenvolvimento realizados por uma fábrica de software externa, a qual possui um controle por ponto de função para os itens que compõem a Dívida Técnica.

Assim como no estudo anterior, o controle da Dívida Técnica é apontado como muito importante. Entre os controles citados pelos respondentes, o mais recorrente é o cadastro do débito técnico na forma de uma lista de pendências priorizadas pelo cliente, ou pela própria equipe quando necessário.

A comunicação da dívida torna-se mais fácil conforme o grau de envolvimento do cliente no processo de desenvolvimento. Nos projetos cujos sistemas estavam em desenvolvimento ou sofreram alterações frequentes, o grau de envolvimento do cliente é muito alto, proporcionando, assim, uma comunicação tranquila e compreendida pelo cliente. Nos demais projetos, a comunicação se torna mais complicada de ser realizada e nem sempre é compreendida pelo cliente.

De forma similar, nas duas pesquisas, os resultados vistos nesse item indicam que os respondentes que atuam também como desenvolvedores preferem não assumir uma Dívida Técnica, porém os respondentes que atuam apenas como gestores estão mais dispostos a assumir a dívida. Também foi destacado que a Dívida Técnica nem sempre é planejada, havendo circunstâncias em que a solução adotada é a mais cor- 
reta no presente, porém torna-se uma dívida no futuro, em decorrência da evolução tecnológica.

Em ambos os estudos é possível concluir que a dívida é vista como algo inevitável. Na opinião da grande maioria dos respondentes ela é necessária para atender às necessidades do cliente e às exigências de mercado. Diante dessa posição, o mais importante é encontrar estratégias para gerenciá-la, mesmo que não exista um consenso na forma de aplicação desse gerenciamento.

No estudo anterior foi sugerido como possibilidade utilizar a estratégia "Não fazer nada," "Se não está quebrado, não conserte," "Porque a dívida pode nunca se tornar visível para o cliente”; porém, no estudo atual essa estratégia não foi levantada por nenhum dos respondentes. Nos casos relatados percebe-se que a dívida, quando reconhecida, deve ser paga, mesmo que não se tenha conhecimento de quando será paga.

Outra sugestão do estudo anterior é tornar a dívida explícita, comunicando os seus custos e benefícios a todas as partes interessadas, contudo, no contexto atual, é acrescentada a essas sugestões a necessidade de atribuir maior importância ao processo de medir a dívida, conseguindo determinar o tamanho, calculando o custo estimado e o quanto a dívida afeta exatamente o projeto. A partir da obtenção dessas informações será possível tomar decisões mais consistentes e desenvolver sistemas mais coerentes com a realidade do negócio.

\section{CONSIDERAÇÕES FINAIS}

A expressão Technical Debt é recente na área de e-GOV de TI no contexto local, porém todos os respondentes conseguiram identificar e relatar ao menos um caso de ocorrência de Dívida Técnica em seus projetos. Em 10 casos relatados pelos respondentes, a Dívida Técnica ocorreu de forma consciente, pois os relatos demonstraram que os respondentes e seus colegas estavam envolvidos em avaliar de alguma forma os benefícios e as consequências dos itens que podiam produzir alguma dívida, nos projetos de software em que estavam participando. Apenas dois respondentes relataram que a dívida foi assumida ao se gerar um código imaturo.

A comunicação da dívida, em dez casos, era comunicada a todos os envolvidos com o projeto de forma direta, ou seja, analistas, equipe de desenvolvimento e chefias. Nos projetos nos quais os clientes tinham maior envolvimento, os próprios clientes participavam ativamente das decisões, em relação a assumir ou pagar a dívida conforme a realidade do momento. Alguns respondentes apontaram que um importante fator para evitar contrair uma Dívida Técnica desnecessária, ou que favorece o 
pagamento de dívidas já existentes, seria a formação de equipes com a correta quantidade de profissionais, que possuam o conhecimento necessário para desenvolver as atividades exigidas pelo projeto.

Notadamente, apesar de o contexto divergir da pesquisa de Lim, Taksande e Seaman (2012), o Technical Debt se mantém ainda como um conceito explicativo relevante. A maioria dos respondentes busca atender às necessidades do cliente em primeiro lugar, priorizando a entrega de algo importante pelo ponto vista do cliente, como consequência, produzindo uma Dívida Técnica. A dívida contraída é de conhecimento da equipe de desenvolvimento, porém não há uma preocupação ou, até mesmo, uma priorização em determinar o tamanho total dessa dívida em número de itens a serem implementados ou corrigidos, e, por consequência, o valor financeiro da dívida é desconhecido.

Nos projetos abordados nesta pesquisa, os analistas de sistemas tomavam a decisão em assumir a dívida técnica, contudo, as decisões não eram embasadas nos custos envolvidos. Os analistas tinham uma visão vaga sobre os custos, consequentemente, não era uma das suas maiores preocupações. Todavia, quando o custo é preterido nesse tipo de decisão, há grande possibilidade de o projeto tornar-se mais caro que o esperado (GUO; SPÍNDOLA; SEAMAN, 2014), favorecendo o aumento da Dívida Técnica.

Portanto, nota-se a ausência de mecanismos de comunicação adequada estipulados por um gerenciamento de comunicação eficaz. Por outro lado, caso os gestores de contratos repassassem os custos diretos e indiretos aos tomadores de decisão do projeto, a Dívida Técnica poderia ser reduzida ou não assumida. Nessa hipótese, o gerenciamento da integração gerenciaria as mudanças no tempo, no escopo e nas pessoas envolvidas, com base nos custos (PMI, 2013).

Em síntese, dois aspectos foram destacados por todos os respondentes: todos os respondentes sugeriram gerenciar a Dívida Técnica de alguma forma que esteja sempre visível às equipes e utilizar técnicas para eliminar a dívida no menor prazo possível, como, por exemplo, a utilização de uma lista de tarefas atualizada e de conhecimento de toda a equipe do projeto de desenvolvimento de software, bem como de conhecimento do cliente do projeto; todos os respondentes afirmaram, de formas diferentes, que contrair uma Dívida Técnica auxilia a obtenção de resultado imediato com entregas dentro dos prazos, mesmo que o resultado entregue não seja o ideal em termos de qualidade ou de funcionalidades, porém é imprescindível que os tomadores da decisão de contrair ou não a dívida estejam cientes e preparados para tratar das consequências dessa dívida, procurando manter um equilíbrio entre o uso adequado e 
consciente de Dívida Técnica e o atendimento das expectativas do cliente e a realidade do negócio.

O mais preocupante, entre os resultados, é que o atendimento de demandas de projetos de e-GOV está priorizando o escopo e o prazo, com a possibilidade de comprometer a qualidade em longo prazo, com risco à qualidade dos sistemas e à possibilidade de comprometer a integridade dos dados dos cidadãos e a disponibilidade dos serviços fornecidos pelo Governo.

Os resultados obtidos nesta pesquisa não são generalizáveis e refletem um contexto local em projetos específicos de Governo Eletrônico Remanescem algumas sugestões para futuros estudos sobre o tema abordado nesta pesquisa: estudo de estratégias que favoreçam o gerenciamento da Dívida Técnica no contexto local; estudos de cases de gerenciamento da Dívida Técnica; e, estudo para identificar novas formas de calcular o custo da dívida assumida. Portanto, por tratar-se de um tema muito importante na área de desenvolvimento de software, merece uma série de novas pesquisas, que poderão enriquecer ainda mais o conhecimento a respeito desse assunto.

\section{REFERÊNCIAS}

ANTHOPOULOS, L. et al. Why e-government projects fail? An analysis of the Healthcare. Government Information Quarterly, 2015.

BAVANI, R. Distributed agile, agile testing, and technical debt. IEEE Software, v. 29, i. 6, p. 28-33, 2012.

CUNNINGHAM, W. The WyCash Portfolio Management System. OOPSLA '92 Experience Report, 1992. Disponível em: <http://c2.com/doc/oopsla92.html>. Acesso em: 01 jun. 2013.

CURTIS, B.; SAPPIDI, J.; SZYNKARSKI, A. Estimating the size, cost, and types of Technical Debt. In: MANAGING TECHNICAL DEBT (MTD), 3., 2012, Zurich. Anais... Zurich: IEEE, 2012. Disponível em: <http://ieeexplore.ieee. org/xpl/login. jsp?\%20tp=\&arnumber=6226000\&url=http\%3A\%2F\%2Fieeexplore.ieee.org\%2Fxpls\%2Fabs_all.jsp\%3Farnumber\%3D6226000>. Acesso em: 01 jul. 2012.

FOWLER, M. Technical Debt. MartinFowler.com, 2009a.

Disponível em: <http://www.martinfowler.com/bliki/TechnicalDebt.html>. Acesso em: 01 jun. 2013.

FOWLER, M. Technical Debt Quadrant. MartinFowler.com, $2009 b$. 
Disponível em: <http://www.martinfowler.com/bliki/TechnicalDebtQuadrant.html> . Acesso em: 01 jun. 2013.

GUO, Y.; SPÍNOLA, R. O.; SEAMAN, C. Exploring the costs of technical debt management - a case study. Empirical Software Engineering, p. 1-24, 2014.

HAIR JUNIOR, J. F. et al. Fundamentos de métodos de pesquisa em administração. 7. ed. Porto Alegre: Bookman, 2005.

IEEE COMPUTER SOCIETY. Interview Guide - Focus: Technical Debt. Disponível em: <http://www.computer.org/cms/Computer.org/dl/mags/so/2012/06/ extras/mso2012060022s.pdf>. Acesso em: 12 jun. 2013.

KRUCHTEN, P.; NORD, R. L.; OZKAYA, I. Technical debt: from metaphor to theory and practice. IEEE Software, i. 6, p. 18-21, 2012.

KUMAR, V. et al. A factors for successful e-government adoption: a conceptual framework. The electronic journal of e-Government, v. 5, i. 1, p. 63-76, 2007.

LIM, E.; TAKSANDE, N.; SEAMAN, C. A balancing act: what software practitioners have to say about technical debt. IEEE Software, v. 29, i. 6, p. 22-27, 2012.

MCCONNELL, S. Technical debt. Construx, 2007. Disponível em: <http://blogs. construx.com/blogs/stevemcc/archive/2007/11/01/technical-deb t-2.aspx >. Acesso em: 07 jul. 2013.

ORGANIZAÇÃO DAS NAÇÕES UNIDAS. E. government Survey (2012) E-Government for the people. New York: United Nations, Department Economic and Social Affairs, 2012.

PMI. A Guide to the Project Management Body of Knowledge (PMBOK). Project Management Institute, 2013.

SEAMAN, C. et al. Using technical debt data in decision making: potential decision approaches. In: MANAGING TECHNICAL DEBT (MTD), 3., 2012, Zurich. Anais... Zurich: IEEE, 2012. Disponível em: <http://ieeexplore.ieee.org/xpl/articleDetails.jsp?re load=true\&arnumber= 6225999>. Acesso em: 14 jul. 2013. 


\section{APÊNDICE A - Guia de Entrevista - versão traduzida (IEEE, 2012)}

Ward Cunningham usou o termo "débito técnico" como uma metáfora para representar as consequências de fazer o trade-off(dilema, mutuamente exclusivo) entre a tomada de decisão de usar atalhos/implementação de um sistema de software totalmente arquitetado e sustentável para entregar o sistema rapidamente para o cliente. O objetivo desta entrevista é identificar como projetos caracterizam e decidem assumir e gerir a dívida técnica.

Exemplo de dívida técnica: -Não evolui com o avanço da tecnologia, gera uma dívida técnica (atualização de software, hardware). -Caminho mais barato, resolvo algo mais simples e deixo o mais tarde apto por complementar no futuro.

\section{Contexto}

1.1 Fale sobre você em TI:

1.1.1 Quantos anos de experiência você tem?

1.1.2 Qual é o seu papel no projeto?

1.1.3 Quais são as suas responsabilidades?

1.1.4 Quantos anos você trabalhou no projeto?

1.2 Descreva seu projeto:

1.2.1 O que o sistema faz?

1.2.2 Quantos anos tem o sistema?

1.2.3 Quem são seus clientes (segmento de mercado)?

1.2.4 Qual é o processo de desenvolvimento de software no projeto?

1.2.5 Qual é o processo de planejamento de entregas no projeto?

2 Dívida Técnica

2.1 Descreva um exemplo de Dívida Técnica em seu projeto.

2.1.1 O que aconteceu?

2.1.2 Por que você considera que seja "Dívida Técnica”

2.1.3 Você planejou adquirir a "Dívida Técnica”?

2.1.3.1 Se sim...

2.1.3.1.1 Quem tomou a decisão de assumir a dívida?

2.1.3.1.2 Quando você decidiu assumir a dívida?

2.1.3.1.3 Por que você decidiu assumir a dívida?

2.1.3.1.4 Como você decidiu assumir a dívida?

2.1.3.2 Se não...

2.1.3.2.1 Quem identificou que essa é uma dívida?

2.1.3.2.2 Quando descobriu a dívida? 
2.1.3.2.3 Por que você decidiu que é uma dívida?

2.1.3.2.4 Como você descobriu a dívida?

2.1.4 Qual é o impacto da dívida técnica em seu projeto?

2.1.4.1 Para os clientes?

2.1.4.2 Para o desenvolvimento?

2.1.4.3 Para futuras modificações no sistema?

2.1.5 Você sabe o quanto o sistema é afetado pela dívida? Se sim, como você mede o tamanho da dívida?

2.1.6 Como você está administrando a dívida? Há algum plano para pagar a dívida?

\title{
2.1.7 Como você comunica a dívida?
}

Aos seus clientes? Aos seus gerentes? Aos seus desenvolvedores?

2.1.8 Quais são os benefícios de assumir a dívida?

2.1.9 Quais são as consequências de assumir a dívida?

2.1.10 Contrair a dívida vale a pena? Você faria isso de novo?

2.1.11 O que você aprendeu com essa experiência? O que você faria igual/ diferente?

Como citar este artigo:

\author{
ABNT \\ KLEIN, Deisy Cristina Barbiero; KLEIN, Rodrigo Hickmann; LUCIANO, Edimara \\ Mezzomo. Technical Debt em projetos de Governo Eletrônico no estado do Rio \\ Grande do Sul. RACE, Revista de Administração, Contabilidade e Economia, \\ Joaçaba: Ed. Unoesc, v. 15, n. 3, p. 797-820, set./dez. 2016. Disponível em: <http:// \\ editora.unoesc.edu.br/index.php/race>. Acesso em: dia/mês/ano.
}

\begin{abstract}
APA
Klein, D. C. B., Klein, R. H., \& Luciano, E. M. (2016). Technical Debt em projetos de Governo Eletrônico no estado do Rio Grande do Sul. RACE, Revista de Administração, Contabilidade e Economia, 15(3), 797-820. Recuperado em dia/mês/ano, de http://editora.unoesc.edu.br/index.php/race
\end{abstract}

